\title{
TOPSIS ve MAUT Yöntemleri ile İçmesuyu Dağıtım Sistemlerinde Rehabilitasyon Önceliğinin Belirlenmesi
}

\author{
Şeymanur GÜL ${ }^{1}$, Mahmut FIRAT ${ }^{2 *}$ \\ ${ }^{1}$ İnşaat Mühendisliği Bölümü, Fen Bilimleri Enstitüsü, İnönü Üniversitesi, Malatya, Türkiye \\ 2 İnşaat Mühendisliği Bölümü, Mühendislik Fakültesi, İnönü Üniversitesi, Malatya, Türkiye \\ 1 seyma4417@gmail.com,*2 mahmut.firat@inonu.edu.tr
}

(Geliş/Received: 19/02/2020;

Kabul/Accepted: 08/11/2020)

Öz: İçmesuyu dağıtım sistemlerinde meydana gelen arızaların sıklığının artmasına bağlı olarak hizmet kalitesi düşmekte ve işletme maliyetleri artmaktadır. Bu nedenle İçmesuyu dağıtım sistemlerinde risk değerlendirmesi, şebeke rehabilitasyon programının oluşturulması ve varlık yönetimi kapsamında analiz ve değerlendirmelerin yapılması sistem yönetimi açısından oldukça önemlidir. Bu çalışma kapsamında, çoklu ölçütlü karar verme yöntemleri ile içmesuyu dağıtım sistemlerinde şebeke rehabilitasyonunda öncelikli bölgelerin belirlenmesi amaçlanmıştır. Bu amaçla, öncelikle literatür incelemesi yapılarak verisi ölçülebilen, uygun, karşılaştırılabilir ölçütler çerçevesinde toplam 28 faktör belirlenmiştir. Belirlenen bu faktörlerin etki derecesini belirlemek ve ağırlıkları hesaplanmak için ENTROPI yöntemi uygulanmıştır. Hesaplanan ağırlık katsayılarının problemin doğal yapısı ile uyumlu olduğu görülmüştür. Faktörlere ait ağırlıklar ve saha verileri kullanılarak Technique for Order Preference by Similarity to Ideal Solution (TOPSIS) ve Multi-attribute utility theory (MAUT) yöntemleri ile ayrı ayrı analiz yapılmıș, öncelik sıralaması yapılmış ve sonuçlar değerlendirilmiştir. Yapılan değerlendirmelerde her iki yöntem ile belirlenen bölgelerin benzer olduğu görülmüştür.

Anahtar kelimeler: İçmesuyu dağıtım sistemi, rehabilitasyon, çoklu ölçütlü karar verme

\section{Identification of Rehabilitation Priority in Water Distribution Systems by TOPSIS and MAUT Methods}

\begin{abstract}
Due to the increase in the frequency of failures and leakages in water distribution systems, service quality decreases and operating costs increase. Therefore, risk assessment in water distribution systems, establishment of network rehabilitation program and analysis and evaluations within the scope of asset management are very important for system management. In this study, it is aimed to determine the priority regions in network rehabilitation in drinking water distribution systems with multi-criteria decision making methods. For this purpose, a total of 28 factors were determined within the framework of appropriate, comparable criteria whose data can be measured by first making a literature review. ENTROPY method was applied to determine the effect degree of these factors and to calculate their weights. The calculated weight coefficients were found to be compatible with the natural structure of the problem. Weights were analyzed separately using TOPSIS and MAUT methods using weights and field data, priority rankings were made and results were evaluated. In the evaluations made, it was seen that the regions determined by both methods are similar.
\end{abstract}

Key words: Water distribution system, rehabilitation, multi criteria decision making

Giriş

İçmesuyu dağıtım sistemlerinde meydana gelen arıza sıklığına bağlı olarak işletme maliyeti artmakta ve abonelere sunulan hizmet kalitesi azalmaktadır. Ayrıca arıza sıklı̆ının artmasına bağlı olarak sokak bazlı boru değiştirme oranları da artmaktadır. Bu nedenle bu tür sistemlerde "şebeke yenileme" veya "sokak bazlı onarım" stratejileri arasında tercih yapmak gerekmektedir. Buna karar vermek için sistemin fiziksel özellikleri, işletme maliyeti, arıza ve sızıntı oranları gibi birçok faktör göz önünde bulundurulmalı ve analiz yapılmalıdır. Son yıllarda şebeke rehabilitasyonu, arıza oranının tahmini ve ekonomik analiz çerçevesinde çeşitli yöntemler kullanılarak çalışmaların yapıldığı görülmektedir $[1,2,3,4,5,6,7,8]$. Fares [9] tarafından yapılan çalışmada, Kanada'da içme suyu şebekelerinde arızaların risk durumunun değerlendirilmesi, içme suyu şebekesinin korunması için yönetim stratejilerinin uygulanması, maddi ve fiziksel hasarların önlenmesi amaçlanmıştır. Çalışma kapsamında, risk kaynakları 5 grupta incelenmiş olup, Coğrafi Bilgi Sistemleri (CBS) ve Hiyerarşik bulanık uzman sistem ve Analitik Hiyerarşi Süreci (AHP) modeli uygulanmıştır. Çalışmanın sonucunda sistemi etkileyen en yüksek risk faktörünün boru yaşı olduğu saptanmıştır. Sargaonkar vd. [10] yaptığı çalışmada Hindistan'ın Hyderabad kentinde kötü durumdaki kritik boruları belirlemek, kent nüfusuna sürekli ve güvenli su

* Sorumlu yazar: mahmut.firat@inonu.edu.tr. Yazarların ORCID Numarasi: ${ }^{10000-0002-3773-9058, ~}{ }^{20000-0002-8010-9289}$ 
temini sağlamak amacıyla su ve kanalizasyon şebekesi, toprak ve yeraltı suyu CBS haritalarını hazırlamış ve yüksek riskli bölgeler belirlemiştir. Francisque vd. [11] bulanık sentetik değerlendirme, analitik hiyerarşi süreç ve bulanık kümeleme yöntemleriyle su şebekesinde güvenlik açığı, duyarlılık ve risk indekslerinin belirlenmesini amaçlamıştır. Çalışmada, metal borularda korozyona bağlı zararlar ortaya çıkabileceği ve su sıcaklığının artışı bozulmalara sebep olabileceği vurgulanmıştır. Morais ve Almeida [12] kesintisiz, uygun basınçta, kaliteli su temini sağlamak amaciyla Preference ranking organization method for enrichment evaluation (PROMETHEE) yöntemini kullanarak en iyi alternatiflerin alt kümelerini belirlemiş ve sıralamıştır. Roozbahani vd. [13] kentsel su temini yönetiminde karşılaşılan sorunlar için farklı karar verme yöntemlerinin oluşturulması, iklim değişikliğinin su kaynakları üzerindeki etkisinin belirlenmesi amacıyla PROMETHEE I, PROMETHEE II, PROMETHEE-GAIA, PROMETHEE-GDSS metotlarını uygulamıştır. Francisque vd. [14] tarafından yapılan çalışmada Kelowna şehrinin içme suyu dağıtım sistemi incelenmiştir. Su şebekelerinde bakım onarım yenileme strateji önceliğinin sağlanması, metalik, çimento, plastik, AC boruların karşılaştırılması, olası sistem arızalarının belirlenmesi, sudaki klor miktarının optimize edilmesi, su kalitesinin arttırılması hedeflenmiștir. Scholten vd. [15] su dağıtım şebekelerinin stratejik varlık yönetiminde gelecekteki belirsizlikler altında 18 stratejik rehabilitasyon alternatiflerinin değerlendirilmesi için bir çerçeve oluşturulmuştur. Çok kriterli karar analizi, ELimination Et Choice Translating REality (ELECTRE), Varlık Yönetim Yazılımı uygulanmıştır. Alternatifler karşılaştırılmış, sıralanmış ve Boom senaryosu altında duyarlılık analizi yapılmıştır. Marzouk vd. [16] (2015) yaptıkları çalışmada su dağıtım sistemlerinin performansını iyileştirmek, rehabilitasyon teknolojisinin seçimini tanımlamak amacıyla SIMOS algoritmasını uygulamışlardır. Çalışmanın sonucunda karar vericiler için hızlı onarım, karar ve yenileme adımı sağlamak, ARC-MAP ile görselleştirme sağlamak, yaşam döngü maliyetleri ve risklerini minimize etmek hedeflenmiştir. Literatürde incelenen çalışmalardan da görüldüğü üzere, içmesuyu dağıtım sistemlerinde risk değerlendirmesi, şebeke rehabilitasyon programının oluşturulması ve varlık yönetimi gibi alanlarda farklı yöntemler kullanılarak analiz ve değerlendirmeler yapılmıştır. Bu çalışma kapsamında, çoklu ölçütlü karar verme yöntemleri ile içmesuyu dağıtım sistemlerinde şebeke rehabilitasyonunda öncelikli bölgelerin belirlenmesi amaçlanmıștır. Bu amaçla, faktörlere ait ağırlıkların hesaplanmasında ENTROPI yöntemi uygulanmıştır. Faktörlere ait ağırlıklar ve saha verileri kullanılarak TOPSIS ve MAUT yöntemi ile öncelik sıralaması yapılmış ve sonuçlar değerlendirilmiştir. Bu çalışmalar için Malatya merkez içmesuyu dağıtım sisteminde 16 bölge uygulama alanı olarak belirlenmiştir.

\section{2. Çalışma Alanı ve Veri}

\section{1. Çalışma Alanı}

$\mathrm{Bu}$ çalışmada Malatya ili uygulama alanı olarak seçilmiş olup nüfusu 780.000 kişi ve yüzölçümü $12.313 \mathrm{~km}^{2}$ 'dir. Yerleşim, genel olarak şehrin kuzeyinde deniz seviyesinden 690 metre yukarıda olan Karakaya Baraj Gölü kıyıları ile şehrin güneyinde bulunan Beydağının eteklerinde yaklaşık olarak 1200 metre kotları arasında yayılmıştır. Yoğun yerleşimin olduğu bölge ise 900 metre kotlarındadır. Malatya ili metropol bölgesine verilen suyun çok büyük bir bölümü şehrin güneyindeki Beydağlarında deniz seviyesinden 1205 m yukarıda bulunan ve şehrin nerdeyse tamamına cazibe ile su iletme imkanı sunan Pınarbaşı Kaptaj sahasından sağlanmaktadır. İçme suyu şebekesinde kullanılan boru tipleri 2014 yılına kadar AÇB boru, PVC boru, Font Boru, Çelik Boru ve Polietilen borulardır. Malatya Su ve Kanal İdaresi 2014 yılından sonra bahsi geçen boru tiplerini kullanmayı bırakmış ve ağırlıklı olarak Duktil borular kullanılmaya başlanmıştır (MASKİ, 2018). Malatya ilinin güneyindeki yükseltileri oluşturan jeolojik yapılar Doğu Torosların kolu olup yaşlı kayaçlardan oluşmaktadır. Güneybatıdan doğu yönüne doğru uzanan paleozoyik yaşlı metamorfik şistler ve mermer yapılı kireçtaşları bölgedeki en yaşılı kayaçlardır (MASKİ, 2018). Uygulama alanında Su İdaresi şebeke borusu değiştirilmeden sınırları diğer şebeke elemanlarından izole edilmiş 16 İzole Alt Ölçüm Bölge (DMA) oluşturulmuş ve bu çalışma için 16 DMA seçilmiştir [17] (Şekil 1). İzole bölge, su dağıtım şebekesini daha kolay kontrol edebilmek amacıyla birbirinden bağımsız küçük su dağıtım şebekelerine bölünerek oluşturulan su dağıtım şebekeleridir. 


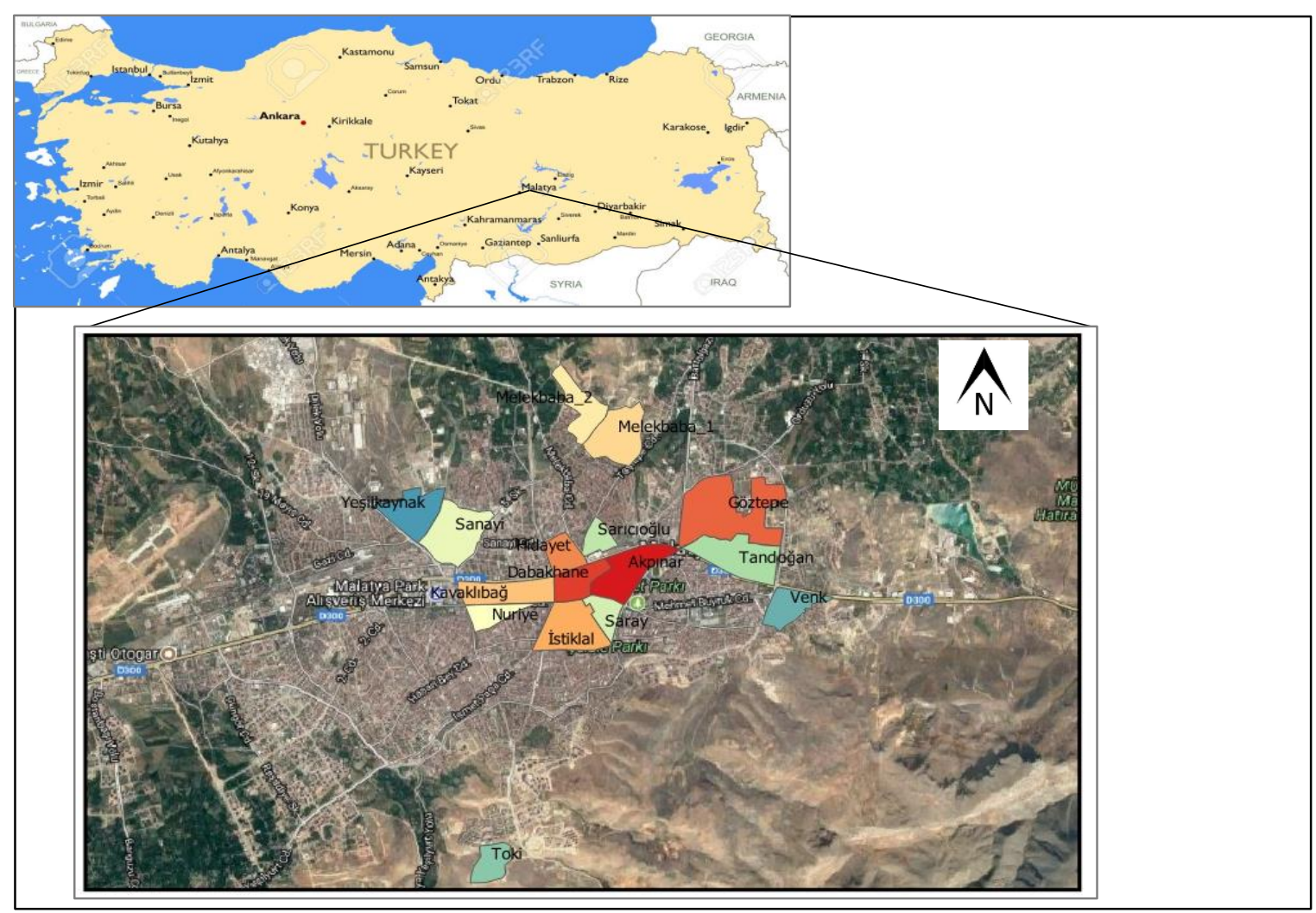

Şekil 1. Uygulama alanı ve izole bölgeler $[17,18]$

\subsection{Faktörler ve Veri Matrisi}

$\mathrm{Bu}$ çalışma kapsamında şebeke rehabilitasyonunda öncelikli bölgelerin belirlenmesi amacıyla ilk olarak problem ile ilgili faktörlerin belirlenmesidir. Etkili faktörler için ağırlık katsayıları hesaplanarak bu faktörlerin önem dereceleri belirlenecektir. Literatürde, arıza ve su kayı analizi ve boru hasarlarının modellenmesi konularındaki çalışmalar incelenmiş ve 156 farklı değişkenin kullanıldığı gözlenmiştir. Ancak bu kadar fazla değişkenin kullanılması, problemin karmaşıklığını arttıracak, verilerin toplanmasında güçlük yaşanacaktır. $\mathrm{Bu}$ nedenle bu çalışmada sistemin mevcut performansını belirlemek ve karar modeli kurmak için uygulanabilirlik, anlaşılabilirlik, ölçülebilirlik, karşılaştırılabilirlik kriterli göz önüne alınarak değiş̧en sayısı 28'e düşürülmüştür [17] (Tablo 1). Uygulanabilirlik ölçütü, çalışmada kullanılacak değişkenlerin, modelin geliştirilmesi ve uygulanmasında uygulanabilir olup olmadığının sorgulanması ve bu değişkenlerin fiziksel, çevresel ve işletme parametreleriyle olan ilişkisinin değerlendirilmesini kapsamaktadır. Anlaşılabilirlik ölçütü, değişkenlerin karar vericiler ve uygulayıcılar tarafından anlaşılabilir olmasını kapsamaktadır. Ölçülebilirlik ölçütü, değişkenlerin ne kadarının kullanılabilir, ulaşılan verilerin ne kadarının sıklıkla ölçülebilir olduğunu ifade etmektedir. Karşılaştırllabilirlik ölçütü, değiş̧enlerin ne kadarının farklı bölgelerde kıyaslanabilir olduğunu açıklamaktadır. Kısaca, modelde kullanılacak değişkenlerin verisinin toplanabilir, ölçülebilir olması, modelin başka bölgelere uygulanabilir olması, bölgelerin bir biri ile kıyaslanabilir olması göz önünde bulundurulmuştur. Burada en önemli nokta, değişkenlerin verilerinin düzenli ve doğru bir şekilde tutuluyor olması gösterilebilir. Verisi düzenli tutulmayan değişkenlerin sisteme dahil edilmesi karmaşıklığı arttırdığı gibi uygulanabilirliği de kısıtlamaktadır. Tabloda, az yoğun trafik 1 olarak; çok yoğun trafik ise 2 olarak ölçeklendirilmiştir. Bölgelerin zemin özellikleri incelenerek arazi tipine göre hareketli ve ortalama zemin olarak ikiye ayrılmış ve ortalama zemin yükü 1; hareketli zemin ise 2 olarak ölçeklendirilmiştir [16]. Merkez ilçelerinde seçilen bu bölgelere ait veriler ve haritalar MASKİ CBS ortamında elde edilmiştir (Tablo 2 ve 3) $[17,18]$. 
Tablo 1. Çalışmada göz önüne alınan değişkenler [17]

\begin{tabular}{|c|c|}
\hline Değişkenler & Açıklama \\
\hline Toplam şebeke uzunluğu (m) (D1) & $\begin{array}{l}\text { Şebeke uzunluğuna bağlı olarak bağlantı sayısı, arıza oranı artmakta ve sistem } \\
\text { yenileme maliyeti yüksek olmaktadır. }\end{array}$ \\
\hline PVC (\%) (D2) & \multirow{2}{*}{$\begin{array}{l}\text { Boru malzemesinin uygun seçilmesi sistemin performansını önemli ölçüde } \\
\text { etkilemektedir. Boru tercihi yapılırken, borunun ekonomik olmasının yanında uzun } \\
\text { ömürlü, dayanıklı, bakım, onarım ve montaj kolay olmalıdır. }\end{array}$} \\
\hline $\mathrm{AÇB}(\%)(\mathrm{D} 3)$ & \\
\hline Boru çap1 <100 (mm) (D4) & \multirow{3}{*}{$\begin{array}{l}\text { Boru çapı, enerji kayıp katsayısını doğrudan etkilemektedir. Boru çapının uygun } \\
\text { seçilmemesi durumunda boruda oluşan basınç kaybını arttırır ve tesisatın ömrünü } \\
\text { kısaltır. }\end{array}$} \\
\hline Boru çap1 $100-250 \mathrm{~mm}$ (D5) & \\
\hline Boru çap1 $>250 \mathrm{~mm}(\mathrm{D} 6)$ & \\
\hline Şebeke arıza sayısı (D7) & \multirow{6}{*}{$\begin{array}{l}\text { Şebeke ve servis bağlantılarındaki arızalar, dağıtım sisteminin yapısal ve hidrolik } \\
\text { kapasitesinin azalmasına neden olur. Boruların kırılması, çatlaması, su akışının } \\
\text { kesilmesi gibi arızaya sebep olan etkenler bir sistemi verimsiz hale getirmektedir. } \\
\text { Şebekede meydana gelen arızaların tespiti, rehabilitasyon için öncelikli bir } \\
\text { parametredir. Rapor edilmeyen sızıntılar, yüzeye çıkmadığ için sahada tespit } \\
\text { edilmediği sürece büyük oranda su kaybı yaşanmakta ve bakım-onarım-işletme } \\
\text { maliyeti artmaktadır. }\end{array}$} \\
\hline $\begin{array}{c}\text { Şebeke arıza oranı }(\operatorname{ar} 1 z a / y 11 / k m) \\
(D 8)\end{array}$ & \\
\hline Servis bağlantı arıza sayısı (D9) & \\
\hline $\begin{array}{l}\text { Servis bağlantı arıza oranı } \\
\text { (arıza/yı1/km) (D10) }\end{array}$ & \\
\hline Abone say1s1 (D11) & \\
\hline Sizınt1 miktarı (D12) & \\
\hline $\begin{array}{c}20 \text { yaşından büyük boru oranı (\%) } \\
\text { (D13) }\end{array}$ & $\begin{array}{l}\text { Boru yaş1 sistemde arızalar üzerinde etkili en önemli faktörlerden biri olup eski } \\
\text { borulardaki kırıklar, arızalar sistemi olumsuz yönde etkilemektedir. }\end{array}$ \\
\hline Servis bağlantısı sayısı (D14) & $\begin{array}{l}\text { Servis bağlantılarında şebekede bulunan boru cinsine uygun olan bağlantı } \\
\text { yapılmaktadır. Arızaların önemli bir kısmı servis bağlantılarında gözlenmekte ve } \\
\text { işletme maliyeti üzerinde etkilidir. }\end{array}$ \\
\hline Y1llı su kesintisi sayıs1 (D15) & $\begin{array}{l}\text { Suyun tüketiciye kaliteli ve verimli bir şekilde ulaştırılması gerekmektedir. Bir } \\
\text { bölgede meydana gelen su kesintilerinin sayısının fazla olması, hizmet kalitesini } \\
\text { düşürmekte ve işletme koşullarını bozmaktadır. }\end{array}$ \\
\hline Arazi durumu (D16) & $\begin{array}{l}\text { Boru montajına, hendek kazısına ve dolgu malzemesinin sıkıştırılması gibi imalat } \\
\text { işlerinde gerekli özen gösterilmezse boru hattında patlamalar yaşanır. Bu } \\
\text { sebeplerden ötürü çalışılan bölgelerin arazi yapısı bilinmelidir. }\end{array}$ \\
\hline Zemin ve toprak özelliği (D17) & \\
\hline $\begin{array}{l}\text { Sokak sinifi }(<20 \mathrm{~m} \text { ve }>20 \mathrm{~m} \\
\text { \%oranları) (D18) }\end{array}$ & Bölgede boruların hizmet verdiği sokak genişliğini ifade eder. \\
\hline $\begin{array}{l}\text { Önemli yapılar ( hastane, okul) } \\
\text { (D18) }\end{array}$ & $\begin{array}{l}\text { Bölgedeki hastaneler, okullar, alışveriş merkezleri vb. su tüketim oranını büyük } \\
\text { ölçüde arttırmaktadır. Bu yapıların olduğu bölgelerde su kesintisinin en az olması } \\
\text { önemlidir. }\end{array}$ \\
\hline Trafik yoğun & $\begin{array}{l}\text { Boru üzerinde meydana gelebilecek hasarlarda etkili olan bir parametredir. Boru } \\
\text { çatlakları ve ezilmeleri ve arızaları önemli ölçüde etkilemektedir. }\end{array}$ \\
\hline $\begin{array}{l}\text { Değiştirilmiş boru yüzdesi (\%) } \\
\text { (D21) }\end{array}$ & Arızaya bağlı olarak sokakta değiştirilen boru oranını temsil eder. \\
\hline Bilinen vana sayıs1 (D22) & $\begin{array}{l}\text { Vanalar sistemin arıza durumunda boşaltılmasına yardımcı olan şebekenin } \\
\text { emniyetli çalışmasını sağlayan elemanlardan biridir. İçme suyu dağıtım } \\
\text { sistemlerinde, alt ölçüm bölgelerini ayırmak, işletme sırasında bakım ve onarım } \\
\text { amaçlı bölgesel tecrit oluşturmada vanaların bilinmesi önemlidir. }\end{array}$ \\
\hline İşletme basınc1 (D23) & $\begin{array}{l}\text { Sistemdeki basınç dalgalanmaları ve değişimleri, boru hasarlarına neden olur, aşırı } \\
\text { şebeke basıncı da sistemi olumsuz etkilemektedir. }\end{array}$ \\
\hline Su Kayıp Oranı (\%) (D24) & $\begin{array}{l}\text { Su kayıpları, sızıntılarından, kaçak bağlantılardan ve sayaç hatalarından } \\
\text { kaynaklanır. Sistem işletme ve su üretim maliyeti üzerinde etkilidir. }\end{array}$ \\
\hline İşletme maliyeti (TL/y1l) (D25) & Sistemde meydana gelen arızalar, işletme maliyeti üzerinde etkilidir. \\
\hline Nüfus (D26) & Hizmet edilen nüfusu temsil eder. \\
\hline $\begin{array}{l}\text { Bölgenin toplam su talebi m3/yıl } \\
\text { (D27) }\end{array}$ & \multirow{2}{*}{$\begin{array}{l}\text { Su talebi, belirli bir zaman periyodu içinde belli bir nüfusun ihtiyaç duyduğu su } \\
\text { miktarını ifade eder. Alt ölçüm bölgelerde uygun rehabilitasyon yöntemleri ile su } \\
\text { kayıpları azaltılabilir. }\end{array}$} \\
\hline $\begin{array}{l}\text { Bölgenin su talebi 1/kişi*gün } \\
\text { (D28) }\end{array}$ & \\
\hline
\end{tabular}


Tablo 2. Bölgelerde faktörlere ait veriler $[17,18]$

\begin{tabular}{|c|c|c|c|c|c|c|c|c|c|c|c|c|c|c|}
\hline \multicolumn{2}{|c|}{ BÖLGE No ve ADI } & D1 & D2 & D3 & D4 & D5 & D6 & D7 & D8 & D9 & D10 & D11 & D12 & D13 \\
\hline DMA 1 & Hidayet & 4350 & 72.4 & 22.1 & 0.66 & 94.53 & 4.81 & 70 & 1.61 & 207 & 4.76 & 1405 & 10 & 78.5 \\
\hline DMA 2 & Sarıcığlu & 7543 & 61.3 & 20.7 & 0.45 & 67.67 & 31.88 & 63 & 0.84 & 78 & 1.03 & 1321 & 14 & 62.8 \\
\hline DMA 3 & Saray & 7991 & 83.5 & 2.9 & 0.76 & 86.43 & 12.81 & 148 & 1.85 & 112 & 1.40 & 2515 & 8 & 85.3 \\
\hline DMA 4 & Kavaklıbăg & 6705 & 74.8 & 19.6 & 1.68 & 89.43 & 8.89 & 228 & 3.40 & 37 & 0.55 & 2832 & 36 & 54.0 \\
\hline DMA 5 & Dabakhane & 9710 & 43.7 & 29.6 & 2.81 & 55.84 & 41.35 & 221 & 2.28 & 91 & 0.94 & 2872 & 44 & 76.4 \\
\hline DMA 6 & Toki & 27383 & 46.1 & 17.3 & 15.97 & 72.85 & 11.20 & 7 & 0.03 & 28 & 0.10 & 1565 & 0.1 & 83.0 \\
\hline DMA 7 & Yeşilkaynak & 29778 & 83.5 & 14.1 & 0.78 & 96.10 & 3.12 & 128 & 0.43 & 54 & 0.18 & 770 & 7 & 75.3 \\
\hline DMA 8 & Akpınar & 19798 & 71.2 & 20.2 & 10.90 & 82.74 & 6.37 & 336 & 1.70 & 54 & 0.27 & 4507 & 29 & 67.9 \\
\hline DMA 9 & Nuriye & 13205 & 57.5 & 25.1 & 0.23 & 76.29 & 23.47 & 194 & 1.47 & 44 & 0.33 & 2446 & 6 & 51.7 \\
\hline DMA 10 & Venk & 5004 & 87.3 & 2.9 & 1.94 & 95.04 & 3.02 & 98 & 1.96 & 91 & 0.10 & 1282 & 0.1 & 85.7 \\
\hline DMA 11 & İstiklal & 14825 & 46.4 & 17.0 & 14.05 & 74.13 & 11.81 & 339 & 2.29 & 137 & 0.92 & 5655 & 35 & 87.0 \\
\hline DMA 12 & Tandoğan & 2739 & 0.1 & 0.1 & 1.24 & 98.76 & 0.10 & 181 & 6.61 & 184 & 6.72 & 2382 & 21 & 0.1 \\
\hline DMA 13 & Göztepe & 13386 & 72.2 & 16.1 & 1.38 & 88.32 & 10.29 & 330 & 2.47 & 159 & 1.19 & 2836 & 20 & 80.1 \\
\hline DMA 14 & Sanayi & 19543 & 31.1 & 7.6 & 10.50 & 61.73 & 27.78 & 210 & 1.07 & 76 & 0.39 & 1510 & 36 & 32.3 \\
\hline DMA 15 & Melekbaba1 & 19122 & 74.7 & 11.7 & 1.74 & 96.85 & 1.41 & 93 & 0.49 & 190 & 0.99 & 1183 & 2 & 53.8 \\
\hline DMA 16 & Melekbaba2 & 22775 & 55.9 & 14.3 & 15.91 & 76.44 & 7.65 & 102 & 0.45 & 190 & 0.83 & 604 & 4 & 77.6 \\
\hline
\end{tabular}

Tablo 3. Bölgelerde faktörlere ait veriler $[17,18]$

\begin{tabular}{|c|c|c|c|c|c|c|c|c|c|c|c|c|c|c|c|}
\hline BÖLGE & D14 & D15 & D16 & D17 & D18 & D19 & D20 & D21 & D22 & D23 & D24 & D25 & D26 & D27 & D28 \\
\hline DMA 1 & 301 & 12 & 0.9 & 2 & 1.6 & 3 & 2 & 8 & 12 & 55 & 33.29 & 48054 & 6565 & 160358 & 66.9 \\
\hline DMA 2 & 315 & 10 & 1.2 & 2 & 0.75 & 1 & 1 & 5 & 23 & 52 & 76.27 & 50154 & 4121 & 136660 & 90.9 \\
\hline DMA 3 & 454 & 8 & 2.4 & 2 & 0.85 & 3 & 1 & 4 & 23 & 58 & 45.29 & 72389 & 2883 & 137149 & 130.3 \\
\hline DMA 4 & 522 & 18 & 2.5 & 2 & 1.39 & 6 & 2 & 17 & 27 & 42 & 39 & 83433 & 988 & 8.645 & 24.0 \\
\hline DMA 5 & 510 & 3 & 1.6 & 2 & 1.07 & 1 & 1 & 3 & 14 & 51 & 36.87 & 81349 & 3391 & 300900 & 88.7 \\
\hline DMA 6 & 380 & 26 & 0.1 & 1 & 1.49 & 4 & 2 & 15 & 32 & 40 & 30.57 & 4.06 & 10457 & 321888 & 84.3 \\
\hline DMA 7 & 537 & 73 & 2.9 & 2 & 0.96 & 1 & 2 & 20 & 27 & 62 & 56.22 & 85343 & 2506 & 80668 & 88.2 \\
\hline DMA 8 & 678 & 7 & 2.1 & 2 & 0.75 & 5 & 1 & 14 & 21 & 58 & 34.69 & 107935 & 1683 & 250.359 & 407.6 \\
\hline DMA 9 & 384 & 10 & 3.8 & 2 & 1.07 & 2 & 1 & 15 & 24 & 41 & 35.42 & 61212 & 2927 & 262174 & 245.4 \\
\hline DMA 10 & 527 & 28 & 5 & 1 & 0.85 & 4 & 2 & 25 & 37 & 44 & 32.79 & 310 & 21186 & 1127945 & 145.9 \\
\hline DMA 11 & 1179 & 6 & 3.5 & 2 & 0.75 & 6 & 1 & 2 & 74 & 41 & 56.44 & 187588 & 5241 & 282987 & 147.9 \\
\hline DMA 12 & 829 & 48 & 2.6 & 2 & 0.75 & 1 & 1 & 45 & 72 & 46 & 32.81 & 132694 & 8440 & 458237 & 148.7 \\
\hline DMA 13 & 1467 & 37 & 3.8 & 2 & 0.85 & 5 & 2 & 10 & 65 & 59 & 53.69 & 233351 & 9207 & 376041 & 111.9 \\
\hline DMA 14 & 1054 & 22 & 1.6 & 2 & 0.85 & 1 & 1 & 15 & 28 & 56 & 57.24 & 167545 & 3545 & 331341 & 256.1 \\
\hline DMA 15 & 949 & 19 & 6.6 & 1 & 0.96 & 4 & 1 & 25 & 40 & 43 & 68.29 & 150778 & 5204 & 202057 & 106.4 \\
\hline DMA 16 & 575 & 36 & 4.3 & 1 & 1.07 & 1 & 1 & 5 & 10 & 45 & 68.29 & 91381 & 6928 & 202057 & 79.9 \\
\hline
\end{tabular}

\section{Yöntem}

\subsection{Topsis Yöntemi}

TOPSIS yöntemi, ELECTRE yönteminin temel yaklaşımlarını kullanarak Hwang ve Yoon [19] tarafından oluşturulmuştur. Pozitif ideal çözüme en yakın olarak belirlenen alternatif, negatif ideal çözüme de en uzak alternatif olarak bulunmaktadır [20]. Alternatifler içinden pozitif ideal çözüme yakın, negatif ideal çözüme uzak olanı seçilmektedir. Bu yöntemin uygulanmasında öncelikle karar matrisinin (A) oluşturulması gerekmektedir (denklem 1).

$$
A_{i j}=\left[\begin{array}{ccc}
a_{11} & \cdots & a_{1 n} \\
\vdots & \ddots & \vdots \\
a_{m 1} & \cdots & a_{m n}
\end{array}\right]
$$


Normalize karar matrisinin (X) her bir elemanını hesaplamak için, A matrisinin her bir elemanı, o elemanın bulunduğu sütun değerlerinin kareleri toplamının kareköküne bölünür. Bu adımda bir karar noktası ilgili değerlendirme kriteri, diğer karar noktalarıyla beraber ilişkilendirilir (denklem (2) ve (3)). Normalize karar matrisinin her bir sütunundaki kriterler, o sütundaki ağırlıklarla çarpılarak ağırlıklandırılmış normalize matris elde edilir (denklem 4).

$$
\begin{aligned}
& X_{i j}=\frac{r_{i j}}{\sqrt{\sum_{i=1}^{n} r_{i j}^{2}}} \quad i=1,2, \ldots, m ; j=1,2, \ldots, n \\
& X_{i j}=\frac{1 / r_{i j}}{\sqrt{\sum_{i=1}^{n} 1 / r_{i j}^{2}}} \\
& Y_{i j}=\left[\begin{array}{ccc}
X_{11} * w_{1} & \cdots & x_{1 n} * w_{n} \\
\vdots & \ddots & \vdots \\
x_{m 1} * w_{1} & \cdots & x_{m n} * w_{n}
\end{array}\right]
\end{aligned}
$$

İdeal çözüm setinin $\left(A^{*}\right)$ oluşturulması için en büyük yapma amaçlanmışsa Y matrisindeki ağırlıklandırılmış sütun değerlerinden en büyük olanı seçilir (denklem (5)). Negatif ideal çözüm seti ( $\boldsymbol{A}^{-}$), oluşturulabilmesi için en düşük yapma amaçlanmışsa Y matrisindeki ağırlıklandırılmış sütun değerlerinin en küçükleri seçilir.

$$
\begin{aligned}
& A^{*}=\left\{\left(\max _{i} v_{i j} \mid j \in J\right),\left(\min _{i} v_{i j} \mid j \in J^{\prime}\right\}\right. \\
& A^{-}=\left\{\left(\min _{i} v_{i j} \mid j \in J\right),\left(\max _{i} v_{i j} \mid j \in J^{\prime}\right\}\right.
\end{aligned}
$$

Bu denklemde, $J$ fayda faktörünü, $J^{\prime}$ ise maliyet faktörünü ifade eder, bulunması amaçlanan setler ise $A^{*}=\left\{v_{1}^{*}, v_{2}^{*}, \ldots, v_{n}^{*}\right\}$ ve $A^{-}=\left\{v_{1}^{-}, v_{2}^{-}, \ldots, v_{n}^{-}\right\}$şeklinde gösterilmektedir. Karar noktalarına ait değerlendirme faktörü değerlerinin ideal $\left(S_{i}^{*}\right)$ ve negatif ideal çözüm $\left(S_{i}^{-}\right)$kümesinden sapmalarının hesaplanabilmesi için Euclidian uzaklık yaklaşımından faydalanılır. Her bir karar vermede belirlenen alternatifin ideal çözüme göreli yakınlığının $\left(C_{i}^{*}\right)$ hesaplanması için ideal ve negatif ideal ayrım ölçütleri kullanılır.

$$
\begin{aligned}
& S_{i}^{*}=\sqrt{\sum_{j=1}^{n}\left(v_{i j}-v_{j}^{*}\right)^{2}} \\
& S_{i}^{-}=\sqrt{\sum_{j=1}^{n}\left(v_{i j}-v_{j}^{-}\right)^{2}} \\
& C_{i}^{*}=\frac{S_{i}^{-}}{S_{i}^{-}+S_{i}^{*}}
\end{aligned}
$$

$C_{i}^{*}$ değeri $0 \leq C_{i}^{*} \leq 1$ aralığındaki değerleri içermektedir. $C_{i}^{*}=1$ hesaplanan alternatifin ideal çözüme, $C_{i}^{*}=0$ alternatifin negatif ideal çözüme olan mutlak yakınlığı belirtilmektedir. Alternatifler ideal çözüme göreli yakınlık $\left(C_{i}^{*}\right)$ değerine göre sıralanmaktadır. 


\subsection{Maut Yöntemi}

Çok ölçütlü karar verme metotlarından MAUT yöntemi, Fishburn [21] ve Keeney [22] tarafindan oluşturulmuş ve Loken [23] tarafından geliştirilmiştir. MAUT yöntemi, belirlenen alternatifler arasında bir sıralama oluşturmak amacıyla sistematik şekilde çalışmaktadır. Bu yöntemde karar verme problemine ait faktörler ve alternatifler karar vericiler tarafından belirlenir. Karar matrisinin satırlarında alternatifler, sütunlarında ise faktörler yer almaktadır. Bir önceki adımda belirlenen değerler karar matrisi yardımıyla normalize edilmektedir. Bunun için her alternatif için, en iyi alternatif için 1, en kötü alternatif için 0 atanır (denklem 11) kullanılır. Normalizasyon işleminden sonra fayda değerlerinin belirlenmesi için fayda fonksiyonu kullanılır (denklem 12).

$$
A_{i j}=\left[\begin{array}{ccc}
a_{11} & \cdots & a_{1 n} \\
\vdots & \ddots & \vdots \\
a_{m 1} & \cdots & a_{m n}
\end{array}\right]
$$

$u i(x i)=\frac{x-x i^{-}}{x i^{+}-x i^{-}}$

$U(x)=\sum_{1}^{m} u_{i}\left(x_{i}\right) * w_{j}$

$x i^{+}$; alternatif için en iyi değer, $x i^{-}$; alternatif için en kötü değer, $x$; hesaplanan satırdaki mevcut fayda, $U x$; alternatifin fayda, $u i(x i)$; her kriter ve her alternatif için normalize fayda, $w \mathrm{j}$; ağıllık değeridir.

\subsection{Entropi Yöntemi}

$\mathrm{Bu}$ çalışmada faktör ağırlıklarının belirlenmesinde ENTROPI yöntemi uygulanmıştır. Bu yöntem çok ölçütlü karar verme yöntemi olup faktörlerin ağırlıklarını saha verileri esas alınarak belirlemektedir. Faktör ağırlıklarının hesabında ENTROPI olarak ifade edilen performans puanları elde edilmekte ve bu puanların ne kadar farklılaşmış olduğu prensibine göre belirlenmektedir [24]. Ağırlıkların hesabı için karar matrisi oluşturulmakta ve bu matriste satırlarda alternatifler yer alırken sütunlarda ise probleme ait faktörler bulunmaktadır (denklem 13). Bu veri matrisi, denklem (14) ile normalizasyon işlemi ve denklem (15) ile de Entropi hesabı gerçekleştirilir [24]. Bu yöntemde bu aşamada $d j$ belirsizliği eşitlik (16) yardımıyla ve ağırlıklar ise denklem (17) ile hesaplanır [24].

$$
\begin{aligned}
& X=\left[\begin{array}{lll}
X_{11} & \ldots & X_{1 n} \\
& \ddots & \\
X_{m 1} & \ldots & X_{m n}
\end{array}\right] \\
& r i j=\left(x i j-\min _{j} x j\right)-\left(\max _{j} x j-\min _{j} x j\right) \\
& \mathrm{Ej}=-\mathrm{k} \sum_{\mathrm{j}=1}^{\mathrm{m}} \mathrm{rij} *(\ln (\mathrm{rij})) \\
& d j=1-E j ; \forall j \quad(\mathrm{i}=1 \ldots, \mathrm{m} ; \mathrm{j}=1, \ldots, \mathrm{n}) \\
& w j=\frac{d j}{\sum_{j=1}^{n} d j} ; \forall j
\end{aligned}
$$

$\mathrm{k}$; ENTROPI katsayısı $(\mathrm{k}=(\ln (\mathrm{n}))-1)$, rij; normalize edilmiş değerler, Ej; ENTROPI değeri, $\mathrm{i}$; alternatifler , $\mathrm{j}$; kriterler, rij; normalize edilmiş değer, xij; i. alternatif $\mathrm{j}$. kriter için verilen fayda değerleridir. 
TOPSIS ve MAUT Yöntemleri ile İçmesuyu Dağıtım Sistemlerinde Rehabilitasyon Önceliğinin Belirlenmesi

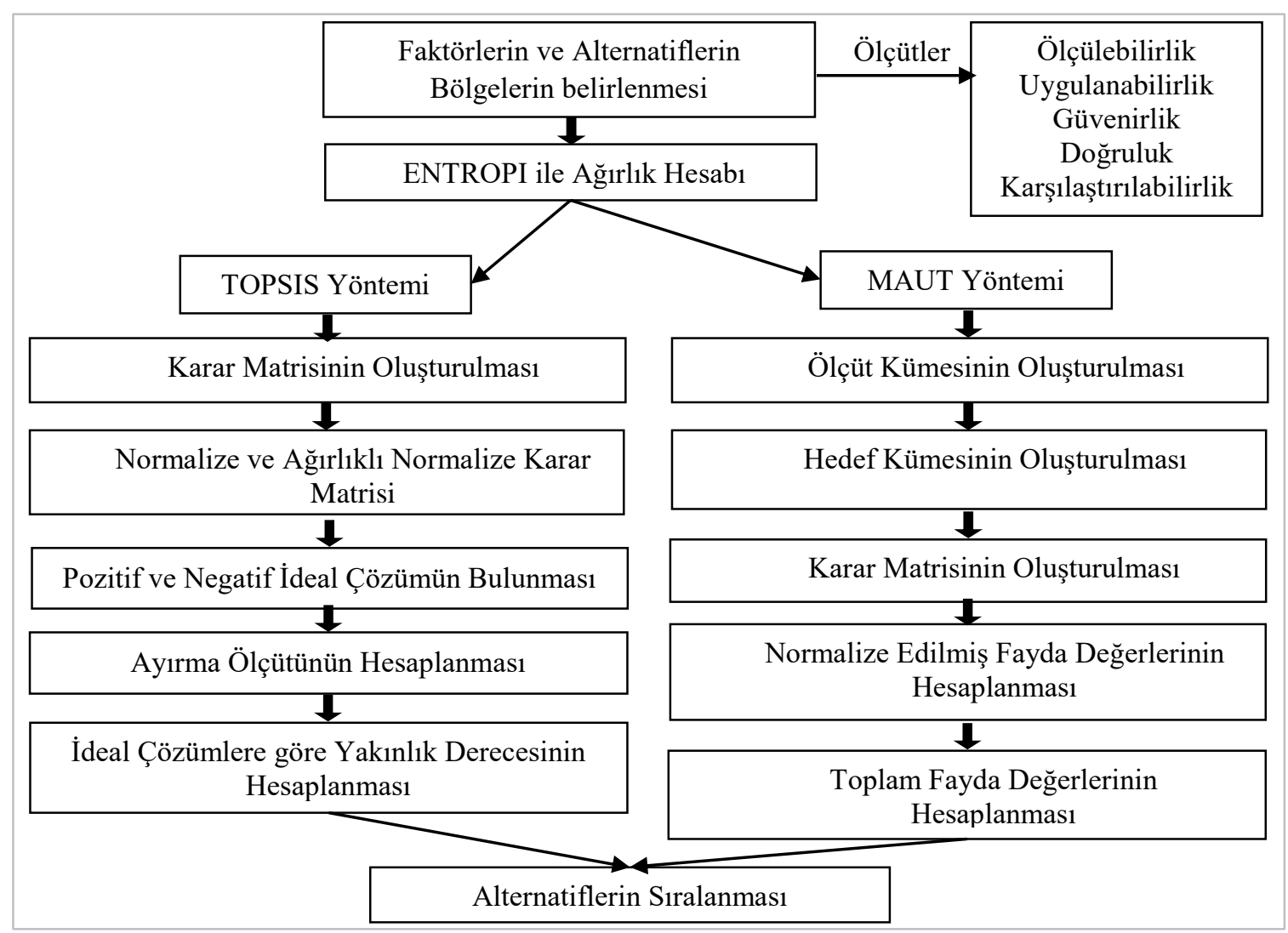

Şekil 2. Akış diyagramı [17]

\section{Analiz ve Değerlendirme}

\subsection{Ağırlıkların Hesabı}

Şebeke rehabilitasyonunda öncelikli bölgelerin belirlenmesinde ilk önce ENTROPI yöntemi ile ağırlık katsayıları hesaplanmıştır. Ağırlık katsayılarının hesabında faktörlere ait veriler (Tablo 4) dikkate alınmıştır. Dağıtım sistemlerinde işletme maliyetini arttıran en önemli bileşenler yüzeye çıkan ve çıkmayan arıza ve sızıntıların bakım-onarım ve tespit çalışmaları gösterilebilir. Bunların sayısının ve sıklığının artmasına bağlı olarak işletme maliyeti artmakta ve hizmet kalitesi de düşmektedir.

Tablo 4. Faktör ağırlıkları [17]

\begin{tabular}{|c|c|c|c|c|c|c|c|}
\hline Faktör & A ğırlık & Faktör & A ğırlık & Faktör & Ağırlık & Faktör & A ğırlı \\
\hline D1 & 0.0298 & D8 & 0.0536 & D15 & 0.0489 & D22 & 0.0277 \\
\hline D2 & 0.0169 & D9 & 0.0266 & D16 & 0.0304 & D23 & 0.0019 \\
\hline D3 & 0.0317 & D10 & 0.1095 & D17 & 0.0059 & D24 & 0.0120 \\
\hline D4 & 0.1071 & D11 & 0.0274 & D18 & 0.0056 & D25 & 0.0420 \\
\hline D5 & 0.0022 & D12 & 0.0677 & D19 & 0.0409 & D26 & 0.0446 \\
\hline D6 & 0.0663 & D13 & 0.0157 & D20 & 0.0103 & D27 & 0.0477 \\
\hline D7 & 0.0311 & D14 & 0.0192 & D21 & 0.04511 & D28 & 0.0315 \\
\hline
\end{tabular}

Tabloda verilen sonuçlar incelendiğinde, en yüksek ağırlık katsayılarının, Tespit edilen sızıntı miktarı, şebeke ve servis bağlantı yüzeye çıkan arıza sayıları, bölgede değiş̧irilmiş boru yüzdesi faktörleri için hesaplandığı görülmektedir. Bölgede değiştirilmiş boru yüzdesi, arıza oranına bağlı olarak sokak bazlı boru değiştirme oranını gösterdiği için arızanın sık gözlendiği bölgelerde boru değiştirme oranı yükselecek ve dolayısıyla da sistem maliyeti artacaktır. Rapor edilmeyen sızıntıların fazla olduğu sistemlerde, şebekenin izlenmesi, sızıntının tespit edilmesi ve onarılması gibi önemli maliyet kalemleri ortaya çıkmakta ve bu sızıntılar 
tespit edilmediği sürece fiziki kayıp oranı artmaktadır. $\mathrm{Bu}$ nedenle, yüzeye çıkan arıza oranının ve rapor edilmeyen sızıntıların fazla olması, su kayıp oranını ve işletme maliyetini arttırmakta ve normal işletme koşullarını bozmaktadır. $\mathrm{Bu}$ nedenle bu sonuçların problemin doğasıyla benzerlik gösterdiği söylenebilir. Tablodaki sonuçlara göre, yıllık su kesinti sayısı için hesaplanan katsayısının da yüksek seviyede olduğu söylenebilir. Su kesintisinin yüksek olduğu bölgelerde, abonelere istenen miktarda su düzenli olarak iletilmediği için sosyal olarak olumsuz etki oluşturmaktadır. Ayrıca, sürekli kesinti yaşanan sistemde, şebeke elemanları sürekli olarak ani basınç değişimlerine maruz kalacağından dolayı yeni arızaların oluşması, işletme maliyetinin artması gibi olumsuz sonuçlar ortaya çıkmaktadır. Sonuç olarak hesaplanan ağırlık katsayılarının sistemin fiziksel yapısı ile uyumlu olduğu ve değişkenlerin temsil oranının gerçeği yansıttığı söylenebilir [17].

\subsection{Rehabilitasyon için Öncelikli Bölgelerin Belirlenmesi}

Çok kriterli karar verme yöntemlerinden biri olan TOPSIS yöntemi ile alternatiflerin belirli kriterler doğrultusunda sıralaması yapılmaktadır. İzole bölgelere ait veriler MS Excel ortamında oluşturularak MATLAB tabanlı geliştirilen karar destek yazılımına aktarılmış ve öncelikli bölgeler belirlenerek sıralanmıştır (Tablo 4). QGIS ortamında rehabilitasyon önceliği olan bölgelerin haritaları koyu renkten açık renge görselleştirilmiştir [17] (Şekil 3). Benzer şekilde MAUT yönteminde hem niteliksel hem de niceliksel kriterler baz alınarak en uygun alternatifi bulmaya yönelik kullanılan bir yöntemdir. MAUT yöntemi, alternatifler arasında karar vermek ve ortak bir temel sağlamak için sistematik şekilde çalışmaktadır. ENTROPI yöntemi ile faktör ağırlıklarının belirlenmesinden sonra ve alternatifler sıralanarak öncelikli bölgeler belirlenmiştir [17] (Tablo 4, Şekil 3).

Tablo 4. Rehabilitasyonda Öncelikli Bölgelerin Nihai Sıralaması [17]

\begin{tabular}{|c|c|c|c|c|c|}
\hline Bölge & Sonuçlar & Siralama (TOPSIS) & Bölge & Sonuçlar & Sıralama (MAUT) \\
\hline Tandoğan & 0.5602 & 1 & İstiklal & 0.5113 & 1 \\
\hline İstiklal & 0.4126 & 2 & Tandoğan & 0.4636 & 2 \\
\hline Hidayet & 0.3876 & 3 & Göztepe & 0.442 & 3 \\
\hline Sanayi & 0.3651 & 4 & Akpınar & 0.4116 & 4 \\
\hline Melekbaba_2 & 0.3622 & 5 & Sanayi & 0.3985 & 5 \\
\hline Dabakhane & 0.3523 & 6 & Dabakhane & 0.3579 & 6 \\
\hline Toki & 0.3514 & 7 & Melekbaba_2 & 0.3489 & 7 \\
\hline Akpınar & 0.3405 & 8 & Kavaklıbağ & 0.3299 & 8 \\
\hline Göztepe & 0.3217 & 9 & Toki & 0.326 & 9 \\
\hline Venk & 0.3156 & 10 & Venk & 0.3181 & 10 \\
\hline Kavaklıbağ & 0.2765 & 11 & Melekbaba_1 & 0.3062 & 11 \\
\hline Sarıcıoglu & 0.2423 & 12 & Hidayet & 0.3036 & 12 \\
\hline Melekbaba_1 & 0.2356 & 13 & Yeşilkaynak & 0.2701 & 13 \\
\hline Yeşilkaynak & 0.2323 & 14 & Nuriye & 0.2653 & 14 \\
\hline Nuriye & 0.2261 & 15 & Saray & 0.2411 & \\
\hline Saray & 0.2051 & 16 & Sarıcı̆glu & 0.229 & 15 \\
\hline
\end{tabular}




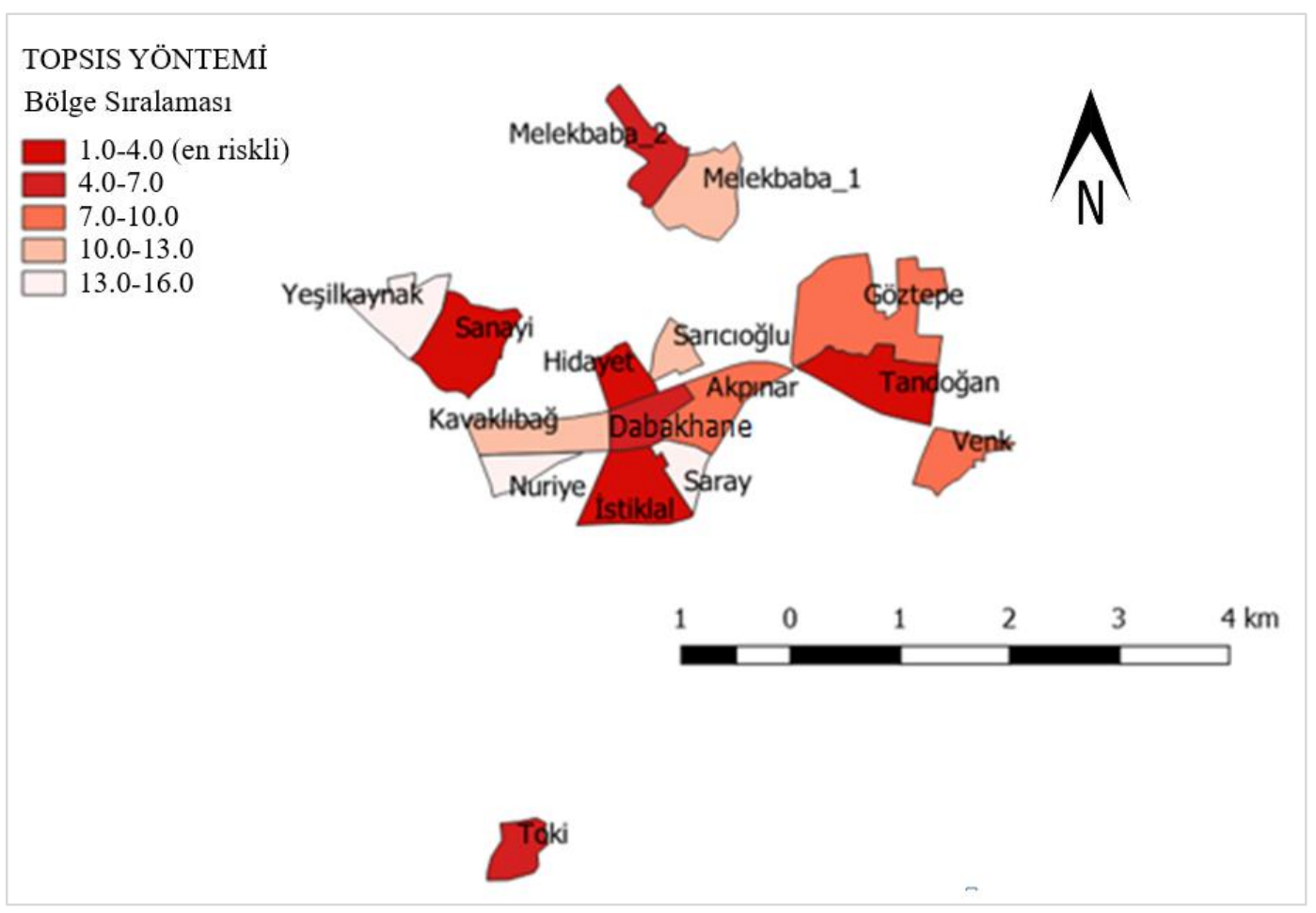

a)

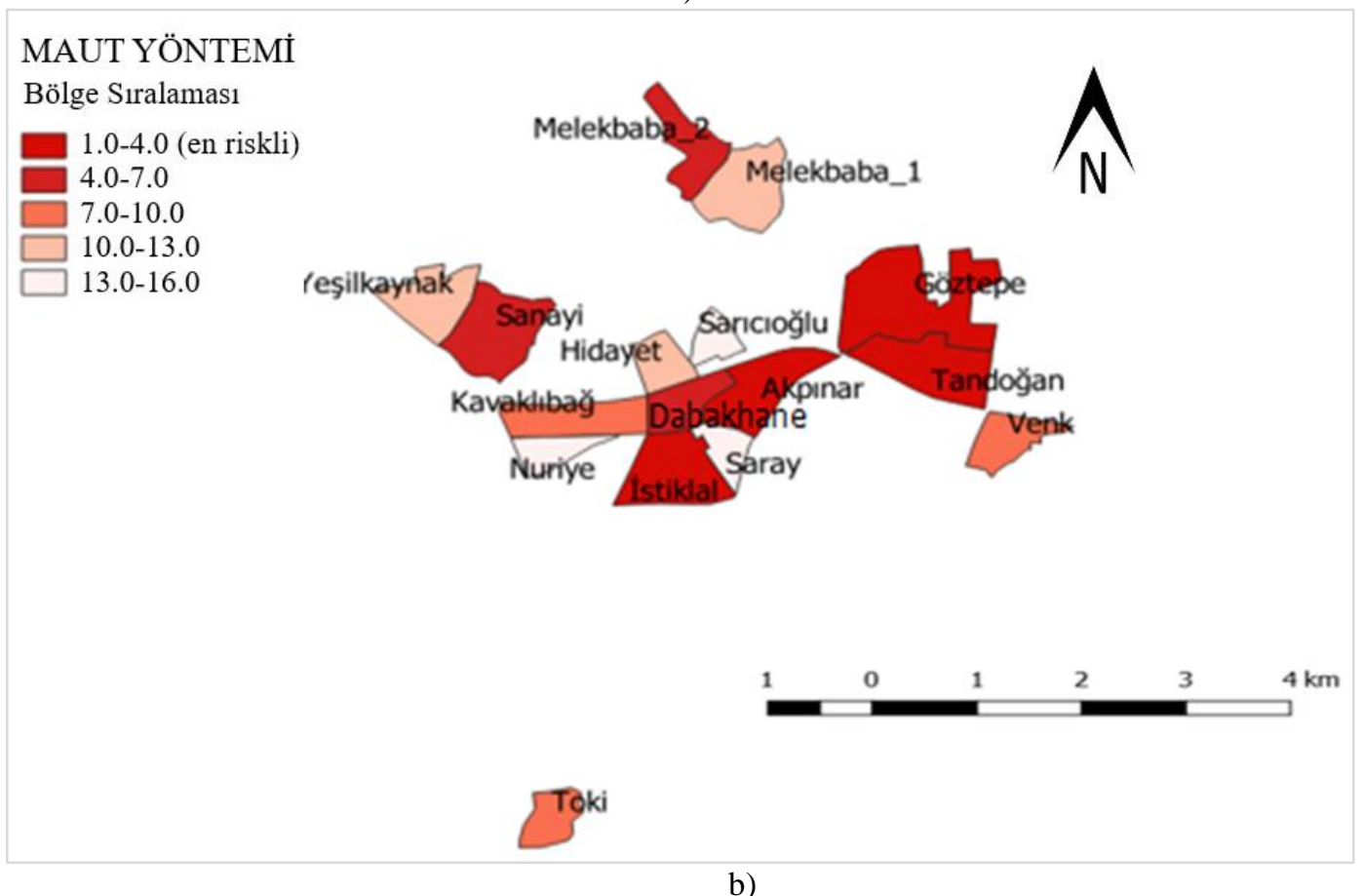

a)Şekil 3. Rehabilitasyonda öncelik sıralaması a) TOPSIS yöntemi b) MAUT yöntemi [17]

Şekil ve tabloda verilen sonuçlara göre, TOPSIS yöntemine göre, rehabilitasyonda öncelikli ilk 5 bölge, Tandoğan, İstiklal, Hidayet, Sanayi ve Melekbaba 2 bölgeleri şeklinde elde edilmiştir. Bu yöntemden elde edilen sonuçlara göre, Yeşilkaynak, Nuriye ve Saray ise diğer bölgelere göre daha iyi durumda olan bölgeler şeklinde değerlendirilebilir. Benzer şekilde MAUT yöntemi sonuçları incelendiğinde, rehabilitasyon önceliği olan bölgelerin sıralamasında ilk 5 bölge temel olarak, İstiklal, Tandoğan, Göztepe, Akpınar ve Sanayi bölgeleri şeklinde oluştuğu görülmektedir. Bu yönteme göre, Nuriye, Saray, Sarıcıoğlu ise diğer bölgelere göre daha iyi 
durumda olan bölgeler şeklinde ifade edilebilir. Her iki yöntem ile elde edilen sonuçlar kıyaslandığında genel olarak rehabilitasyon önceliği olan ilk 5 bölgede 3 bölgenin ortak olduğu görülmektedir. Elde edilen sıralamanın, bölgelerde değişkenlere ait saha verileri ile uyum içinde olduğu söylenebilir. Tablo 2 ve 3 'teki veriler ile değerlendirme yapıldığında, en riskli bölge olarak tanımlanan Tandoğan bölgesinde şebeke ve servis bağlantı arıza oranlarının oldukça yüksek olduğu, su kesinti sayısı ve rapor edilmeyen sızıntı miktarının ise ortalamanın üzerinde olduğu görülmektedir. Diğer taraftan en az riskli olarak tanımlanan Saray mahallesinde, servis bağlantı ve şebeke arıza oranlarının düşük seviyede olduğu, rapor edilmeyen sızıntı miktarı ve su kesinti sayısının yine düşük seviyede olduğu Tablo 2 ve 3 'ten görülmektedir.

Bilindiği üzere su kayıp analizinde ve şebeke yönetiminde iki temel maliyet söz konusudur. Bunlar, arıza, bakım ve onarım ve su kayıpları ile mücadelede yöntemlerin uygulanması ile ortaya çıkan işletme maliyetleri ve şebeke rehabilitasyonu ve boru malzemesi yönetimini içeren ilk yatırım maliyeti şeklindedir. Bu maliyetler, sistemin fiziksel özellikleri, su kayıp oranları, arıza sayıları ve çevresel faktörlerin etkisine bağlı olarak değişmekte ve zamanla kuruma önemli yükler getirmektedir. Özellikle su kayıp yönetiminde şebeke rehabilitasyonu ve boru malzeme değiştirme stratejisi, ilk yatırım maliyetinin yüksek olması, kazı ve inşaat faaliyetlerinden dolayı olumsuz sosyal etkilerinin fazla olması gibi nedenlerden dolayı en son tercih edilmesi gereken yaklaşım olarak önerilmektedir. Bu nedenle, su yönetiminde ve su kayıpları ile mücadelede ilk yatırım maliyetinin düşürülmesinde ve mevcut boru hatlarından en fazla fayda sağlamak için rehabilitasyonda öncelikli bölgelerin belirlenmesi oldukça önemlidir. Bundan dolayı bu çalışmadan elde edilecek sonuçların, su yönetimi ve su kayıpları ile mücadelede idareler için önemli bir referans teşkil edeceği düşünülmektedir.

\section{Sonuçlar}

$\mathrm{Bu}$ çalışmada su kayıplarının önlenmesi amacıyla dağıtım sistemlerinde rehabilitasyonda öncelikli bölgelerin TOPSIS ve MAUT gibi çoklu ölçütlü karar verme yöntemleri ile belirlenmesi amaçlanmıştır. Çalışma kapsamında öncelikli olarak detaylı literatür araştırması yapılarak şebeke yönetiminde etkili olabilecek toplam 28 faktör belirlenmiştir. Çoklu ölçütlü karar verme yöntemlerinin uygulanmasında sadece tek faktörün göz önünde bulundurulması yerine tüm faktörler aynı anda dikkate alındığ 1 için her bir faktörün problem üzerindeki etki düzeyi (ağrılık katsayısı) belirlenmiştir. Bunun için ENTROPI yöntemi uygulanmış ve saha verilerine göre her bir değişkene ait ağırlıklar hesaplanmıştır. Tabloda verilen sonuçlar incelendiğinde, en yüksek ağırlık katsayılarının, tespit edilen sızıntı miktarı, şebeke ve servis bağlantı arıza sayıları, bölgede değiştirilmiş boru yüzdesi faktörleri için hesaplandığı görülmektedir. Sızıntı miktarının ve arıza oranının fazla olması, hizmet kalitesinin düşmesine, sistem işletme maliyetinin artmasına, abone şikayetlerinin artmasına ve su kaynağ verimsizliğine neden olmaktadır. Bu sonuçların problemin doğasıyla benzerlik gösterdiği söylenebilir. Ağırlık katsayılarının hesaplanmasında gerçek saha verileri dikkate alındığından dolayı, problemin doğal yapısını temsil edecek nitelikte ağırlık katsayılarının elde edildiği düşünülmektedir. Çalışmada hesaplanan ağırlık katsayıları ve değişkenlere ait saha verileri esas alınarak TOPSIS ve MAUT yöntemleri ile rehabilitasyonda öncelikli bölgeler belirlenmiştir. TOPSIS yöntemine göre, rehabilitasyonda öncelikli ilk 5 bölge, Tandoğan, İstiklal, Hidayet, Sanayi ve Melekbaba 2 bölgeleri şeklinde elde edilmiştir. Benzer şekilde MAUT yöntemi sonuçları incelendiğinde, rehabilitasyon önceliği olan bölgelerin sıralamasında ilk 5 bölge temel olarak, İstiklal, Tandoğan, Göztepe, Akpınar ve Sanayi bölgeleri şeklinde oluştuğu görülmektedir. Ağırlık katsayılarının doğru bir şekilde hesaplanmış olması ve verilerin doğru bir şekilde ölçülmüş olması, bu tür yöntemlerde model sonuçları üzerinde oldukça etkilidir. Her iki yöntemden elde edilen sonuçların birbirine yakın çıkmasında, ağırlık katsayılarının saha verilerine göre elde edilmesi ve problemin doğal yapısıyla uyumlu olması gösterilebilir. Böylece gerçek veriler dikkate alınarak yapılan analizlerden elde edilen sonuçlar, daha gerçekçi değerlendirme yapma imkanı sunmaktadır. Bu çalışmadan elde edilecek sonuçların, su yönetimi ve su kayıpları ile mücadelede idareler için önemli bir referans teşkil edeceği düşünülmektedir. Ayrıca, şebekede en riskli bölgelerin belirlenmesi ve rehabilitasyona en riskli bölgelerden başlanması kaynakların (su kaynağı. personel ve işgücü. mali kaynakları) daha verimli kullanılması açısından önemli kazanımlar ve katkılar sağlayacağı düşünülmektedir.

\section{Teşekkür}

Bu çalışma, Şeymanur GÜL tarafından tamamlanan Yüksek Lisans Tezinden üretilmiştir. Çalışma, İnönü Üniversitesi Bilimsel Araştırma Projeleri Koordinasyon Birimi (İ̈̈-BAP FYL-2017-583, FOA 2018-626) numaralı projesi ile desteklenmiştir. Yazarlar, desteklerinden dolayı İ̈̈-BAP Birimi’ne, veri ve teknik destekten dolayı MASKİ Genel Müdürlüğü’ne teşekkür etmektedir. 


\section{Kaynaklar}

[1] Choi T, Koo J. A water supply risk assessment model for water distribution network. Desalin. Water Treat, 2015; 54 : $1410-1420$.

[2] Ennaouri I, Fuamba M. New Integrated Condition-Assessment Model for Combined Storm-Sewer Systems. J. Water Resour. Plann. Manage., 2013; 139: 53-64.

[3] Haider H, Sadiq R, Tesfamariam S. Selecting performance indicators for small and medium sized water utilities: Multicriteria analysis using ELECTRE method. Urban Water J. 2015; 12(4): 305-327

[4] Tscheikner-Gratl F. Integrated rehabilitation planning of urban infrastructure systems using a street section priority model. Urban Water J.,2015; 9006: 1-13.

[5] Tsitsifli S, Kanakoudis V, Bakouros I.Pipe Networks Risk Assessment Based on Survival Analysis. Water Resour. Manage. 2011; 25: 3729-3746.

[6] Göral R. Turizm Destinasyonu Rekabetçilik Faktörleri Ve Entropi Yöntemiyle Ağırlıklandırılması. Ekonomi ve Yönetim Araştırmaları Dergisi, 2016; 2: 66-81.

[7] Inanloo B. A decision aid GIS-based risk assessment and vulnerability analysis approach for transportation and pipeline networks. Saf. Sci. 2016; 84: 57-66.

[8] Li Z. Water pipe condition assessment: A hierarchical beta process approach for sparse incident data. Mach. Learn. 2014; 95: 11-26.

[9] Fares H A, Zayed T. Evaluating the Risk of Water Main Failure Using a Hierarchical Fuzzy Expert System. 2008; CSCE 2008 Annual Conference, June 10-13. 1-11.

[10] Sargaonkar A. Risk assessment study for water supply network using GIS. J. Water Supply Res. Technol. AQUA, 2009; 57: 355-360.

[11] Francisque A. Prioritizing monitoring locations in a water distribution network: A fuzzy risk approach. J. Water Supply Res. Technol. AQUA,2009; 58(7): 488-509.

[12] Morais D C, Almeida, ATDe. Water network rehabilitation : A group decision-making approach. WaterSA. 2010; 36(4): 487-494.

[13] Roozbahani A, Zahraie B, Tabesh M. PROMETHEE with Precedence Order in the Criteria (PPOC) as a New Group Decision Making Aid: An Application in Urban Water Supply Management. Water Resour. Manage.. 2012; 26(12): 3581-3599.

[14] Francisque A . A decision support tool for water mains renewal for small to medium sized utilities: A risk index approach. J. Water Supply Res. Technol. AQUA, 2014; 63(4): 281-302.

[15] Scholten L. Strategic rehabilitation planning of piped water networks using multi-criteria decision analysis. Water Research, 2014; 49: 124-143.

[16] Marzouk M, Hamid SA, El-Said M. A methodology for prioritizing water mains rehabilitation in Egypt. HBRC Journal. Housing and Building National Research Center. 2015; 11(1): 114-128.

[17] Gül Ş. Determination of Priority Regions for Rehabilitation in Water Distribution Systems. Master of Science Thesis, İnönü University. 2018.

[18] MASKI (2018). Malatya Water and Sewerage Administration General Directorate. Water Supply Unit Report.

[19] Hwang C-L, Yoon K. Multiple Attribute Decision Making. Lecture Notes in Economic and Mathematical Systems. Springer-Verlag Berlin Heidelberg. 1981; 269. DOI: 10.1007/978-3-642-48318-9

[20] Uzun S, Kazan H. Çok Kriterli Karar Verme Yöntemlerinden AHP TOPSIS ve PROMETHEE Karşıllaştırılması Gemi İnşada Ana Makine Seçimi Uygulaması. J of Transportation and Logistics. 2016; 1(1): 1-18.

[21] Fishburn P. Additive utilities with finite sets: Applications in the management sciences. Naval Research Logistics Quarterly. 1967; 14(1): 1-13.

[22]. Keeney R, Fishburn P. Seven independence concepts and continuous multiattribute utility functions. Journal of Mathematical Psychology, 1974; 11(3): 294-327

[23] Loken E. Use of multicriteria decision analysis methods for energy planning problems. Renewable and Sustainable Energy Rev. 2007; 11: 1584-1595.

[24] Tunca PMZ. Evaluating the Performances of the Opec Countries By Using Entropi and Maut Multi Criteria Decision Making Methods. 2016; 1-12. 